\title{
Sarcoidosis sistémica con afectación de tatuaje
}

\section{Systemic sarcoidosis with affectation of a tattoo}

\author{
Andrés Chavarriaga-Restrepo, Miguel Antonio Mesa-Navas • Medellín (Colombia)
}

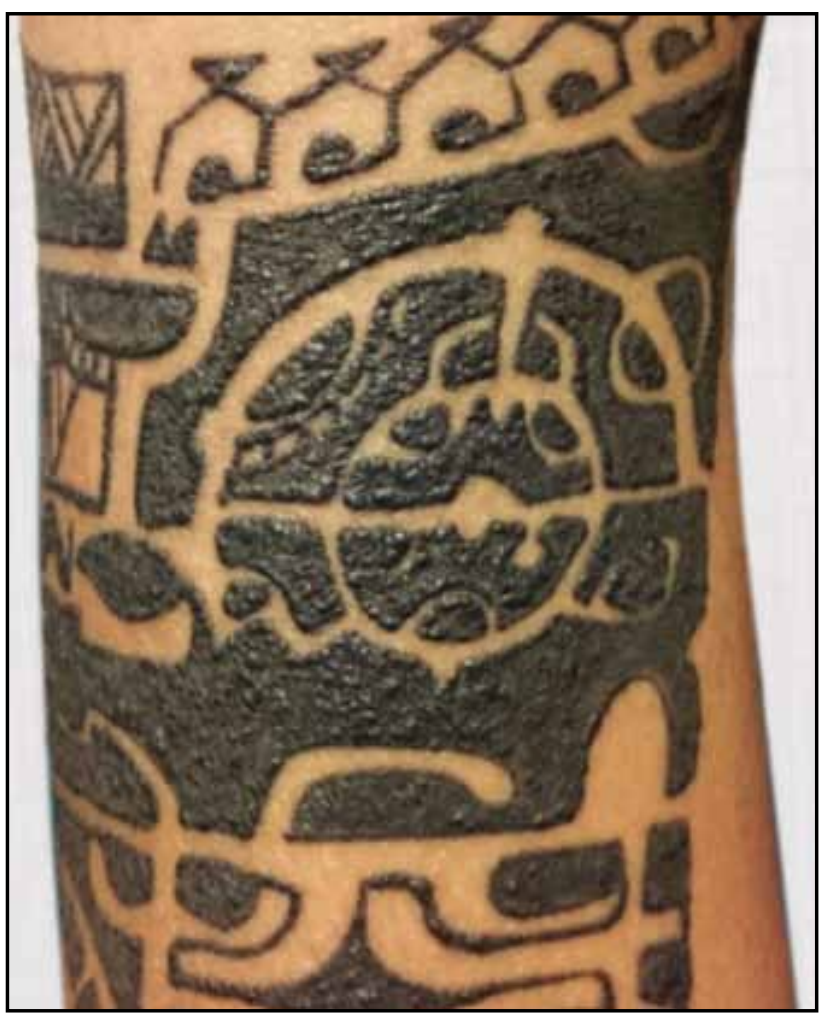

Figura 1. Tatuaje en cara lateral del brazo, infiltrado por múltiples pápulas.
Paciente de 27 años que ingresó a nuestra institución debido a disnea y tos con expectoración, sumado a inyección periquerática, dada por panuveítis con papilitis. Durante el examen físico se observó infiltración de tatuaje dado por pápulas, con posterior confirmación de sarcoidosis cutánea en la biopsia, haciéndose entonces el diagnóstico de sarcoidosis sistémica con panuveítis y afectación pulmonar.

La sarcoidosis del tatuaje es una manifestación común de la sarcoidosis sistémica, presente entre 50 y $75 \%$ de los pacientes (1). Este fenómeno es causado por la exposición crónica antigénica debido a la tinta del tatuaje (2).

En el contexto de un paciente con síntomas sistémicos, es un signo semiológico útil para sospechar esta enfermedad.

\section{Referencias}

1. Antonovich DD, Callen JP. Development of sarcoidosis in cosmetic tattoos. Arch Dermatol. 2005 Jul;141(7):869-72.

2. Ali SM, Gilliam AC, Brodell RT. Sarcoidosis appearing in a tattoo. J Cutan Med Surg. 2008 Feb;12(1):43-8.

Dr. Andrés Chavarriaga-Restrepo: Internista Clínica CES y Hospital San Vicente Fundación; Dr. Miguel Antonio Mesa Navas: Internista - Reumatólogo Clínica Universitaria Bolivariana. Profesor Adscrito Universidad Pontificia Bolivariana. Medellín (Colombia).

Correspondencia: Dr. Andrés Chavarriaga-Restrepo. Medellín (Colombia).

E-mail: andresch_1@hotmail.com

Recibido: 21/V/2018 Aceptado: 8/V/2019 